Mini Review

\title{
New Parameter for Characterization of Dispersed Systems
}

\author{
Sergey Hayrapetyan ${ }^{1}$, Gevorg Simonyan ${ }^{1, *}$ \\ Departament of Chemistry YSU, Armenia \\ *Correspondence: Prof. Dr. Gevorg Simonyan（sim-gev@mail.ru, gevorg.simonyan@ysu.am)
}

How to cite this paper: Hay-

rapetyan, S., \& Simonyan, G. (2022).

New Parameter for Characterization of Dispersed Systems. Online Journal of Materials Science, 1(1), 12-15. Retrieved from https://www.scipublications.com/journal/index.php/materials/article/view/159

Received: October 1, 2021

Accepted: March 2, 2022

Published: March 3, 2022

Copyright: (c) 2022 by the authors. Submitted for possible open access publication under the terms and conditions of the Creative Commons Attribution (CC BY) license (http://creativecommons.org/licenses /by/4.0/).

\begin{abstract}
A new parameter was proposed, with the help of which a specific disperse system was characterized. In addition, a regularity was found showing the relationship between the structural characteristics of structural units (particle size distribution, standard deviation, intensity and average diameter). Various highly dispersed systems have been investigated, including polystyrene latex, Sucrose and latex.
\end{abstract}

Keywords: Particle Size Distribution, Standard Deviation, Intensity, Mean Diameter, Dispersion Parameter

\section{Introduction}

The size distribution of dispersed particles has of particular interest, since many other properties of this material are directly related to it. This includes reactivity, abrasiveness, solubility, extraction and reaction behavior, taste, shrinkage, compressibility, and more. The creation of such materials makes it possible to radically solve the problem of the aggregate stability of nanoparticles, and, consequently, to increase the efficiency and adequacy of assessing their physicochemical characteristics, in particular, morphological features. Thus, nanoparticles of various compositions affect the rheological properties and lubricity of bentonite-based drilling fluids [1].Currently, a large group of methods has been drafted that allow to determine the geometric characteristics of nanoparticles. A brief overview of such methods can be found, for example, in [2-4].

The aim of this work is to obtain reliable information on the physical characteristics of nanoparticles, and to propose a new parameter to characterize a particular disperse system.

\section{Materials and Methods}

The polystyrene latex (PSL), Sucrose and latex were used. For the propose of determination particle size distribution, standard deviation, intensity and mean diameterpurpose, a Mavelrn Zeta Sizer Nano Series instrument was utilized. A $12 \mathrm{~mm}$ polystyrene cell was used to expose the samples to the light beam for the further dynamic light scattering. A characterization of the particle sizes was intended due to the turbid suspension obtained by the addition of the polymer.

\section{Reults and Discussions}

Before moving on to more complex objects, we first examined specific individual materials. Figure 1 shows that the particle size distribution is monomodal. The segment $\mathrm{ob}$ in the figure is Mean Diameter (MD), ab standard deviation (SD), maximum intensity (I). 


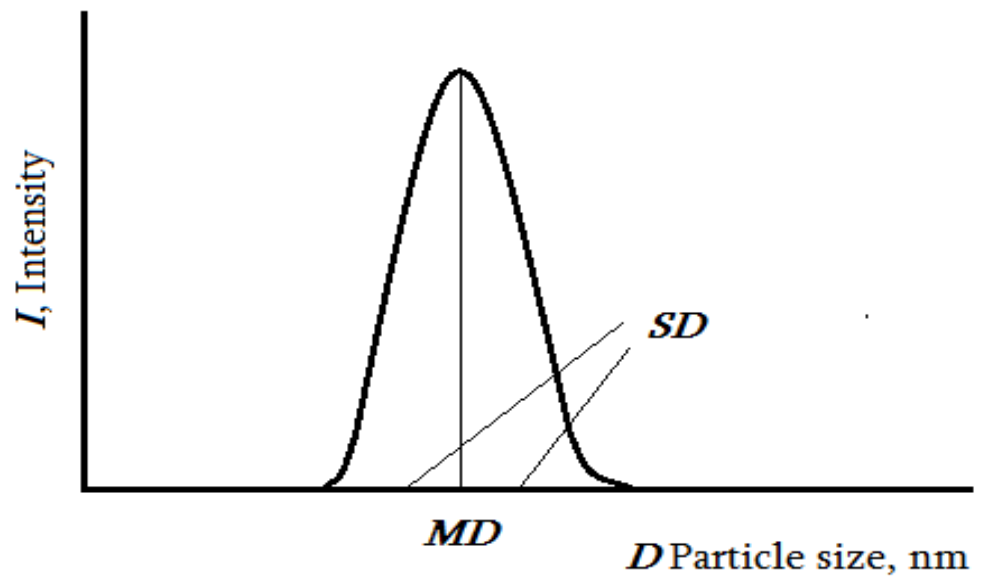

Figure 1. Particle size distribution. Site distribution by intensiti.

We propose a new dispersion parameter (NDP).

$$
N D P=\frac{S D x I}{M D}(1)
$$

The SD, I and MD and NDP values of some particulate materials are shown in Table 1. From Table 1 it follows that the value of dispersibility strictly depends on the properties of a particular material.

This is especially evident from the data obtained on the basis of the Latex series with different particle values from $60 \mathrm{~nm}$ to $1000 \mathrm{~nm}$. Interestingly, for NDP, a value of about 1.6 is obtained, with the mean diameter and standard deviation varying over a very wide range. An illustrative example of the above is the NDP value for the dispersion of polystyrene latexes. Here not only the same values are obtained for particles of $60 \mathrm{~nm}$ and 200 $\mathrm{nm}$, but for a mixture of these particles as well. It is important to note that despite the appearance of bimodal structures, the total NDP value for all peaks gives the NDP value for this very substance. This is also evidenced by sucrose, for which a bimodal structure also appears and the sum of the NDP values is $6 \pm 0.1$.

These three examples clearly show that the NDP value would be a characteristic of a particular substance. It is difficult to explain why a certain substance gives such a constant, but we can say with confidence that each individual substance is dispersed in its own way, individually, and the relationship between the standard deviation, intensity and average diameter has a strictly defined meaning. Of course, many assumptions can be made regarding the explanation of this behavior of a particular substance. It is known that the individuality of dispersed particles is ultimately determined by the chemistry of the surface of the phases. This means that the individuality of a given substance at their NDP is determined by the surface chemistry of these particles. A change in the actual parameters leads to a change in the individuality of the particles and therefore changes in the NDP values are observed. However, the lack of sufficient experimental material does not allow for strong conclusions.

The computer program "Origin-6" was used to analyze the linear relationship between NDP and intensity. It makes a good correlation, as follows:

$\mathrm{NDP}=(0.1403 \pm 0.3421)+(0.2063 \pm 0.0208) \bullet \mathrm{I}, \mathrm{R} 2=0,907676 ; \mathrm{N}=23$. 
Table 1. SD, Intensity, MD and NDP values for some particulate materials.

\begin{tabular}{|c|c|c|c|c|c|c|}
\hline \multirow[b]{2}{*}{ Sample } & \multirow[b]{2}{*}{ Peak } & \multirow[b]{2}{*}{$\mathrm{SD}, \mathrm{nm}$} & \multirow[b]{2}{*}{ Intensity } & \multirow[b]{2}{*}{ MD, nm } & \multicolumn{2}{|c|}{ NDP } \\
\hline & & & & & Peaks & Total \\
\hline 60nm PSL & 1 & 12.72 & 26 & 65.22 & & 5.0708 \\
\hline 60nm PSL & 1 & 14.35 & 24 & 65.94 & & 5.2229 \\
\hline 60nm PSL & 1 & 13.83 & 24.5 & 65.99 & & 5.1346 \\
\hline 200nm PSL & 1 & 40.67 & 25 & 207 & & 4.9118 \\
\hline 200nm PSL & 1 & 48.08 & 22.5 & 208.9 & & 5.1786 \\
\hline 200nm PSL & 1 & 40.66 & 25 & 206.5 & & 4.9225 \\
\hline \multirow{2}{*}{$\begin{aligned} 60 \mathrm{~nm}+200 \mathrm{~nm} & \text { PSL } \\
\text { mixture } & \end{aligned}$} & 1 & 57.37 & 18 & 228.11 & 4.5272 & \multirow[t]{2}{*}{5.0725} \\
\hline & 2 & 8.74 & 4 & 64.11 & 0.5453 & \\
\hline \multirow{2}{*}{$\begin{array}{c}60 \mathrm{~nm}+200 \mathrm{~nm} \text { Latex } \\
\text { mixture }\end{array}$} & 1 & 51.67 & 20 & 222.9 & 4.6361 & \multirow[t]{2}{*}{5.0327} \\
\hline & 2 & 7.544 & 3 & 57.07 & 0.3966 & \\
\hline \multirow{2}{*}{$\begin{array}{c}60 \mathrm{~nm}+200 \mathrm{~nm} \text { Latex } \\
\text { mixture }\end{array}$} & 1 & 51.48 & 20 & 222.6 & 4.6253 & \multirow[t]{2}{*}{5.0655} \\
\hline & 2 & 7.414 & 3.5 & 58.95 & 0.4402 & \\
\hline \multirow{2}{*}{ Sucrose $25 \%(w / v)$} & 1 & 0.2385 & 15.5 & 0.7693 & 4.08053 & \multirow{2}{*}{5.9025} \\
\hline & 2 & 78.08 & 2.5 & 177.9 & 1.0972 & \\
\hline \multirow{2}{*}{ Sucrose $25 \%(\mathrm{w} / \mathrm{v})$} & 1 & 0.2539 & 14 & 0.7568 & 4.6969 & \multirow{2}{*}{5.8803} \\
\hline & 2 & 79.67 & 2.5 & 168.3 & 1.1834 & \\
\hline \multirow{2}{*}{ Sucrose $25 \%(\mathrm{w} / \mathrm{v})$} & 1 & 0.2319 & 16 & 0.7696 & 4.8212 & \multirow{2}{*}{6.1063} \\
\hline & 2 & 74.62 & 3 & 174.2 & 1.2853 & \\
\hline $60 \mathrm{~nm}$ Latex & 1 & 12.25 & 8.5 & 66 & & 1.6163 \\
\hline 100 nm Latex & 1 & 17.66 & 10 & 107.3 & & 1.6458 \\
\hline $300 \mathrm{~nm}$ Latex & 1 & 33.2 & 15 & 309.5 & & 1.609 \\
\hline $500 \mathrm{~nm}$ Latex & 1 & 55.85 & 15 & 522.8 & & 1.6024 \\
\hline $1000 \mathrm{~nm}$ Latex & 1 & 163.8 & 10.5 & 1051 & & 1.6364 \\
\hline
\end{tabular}

\section{Conclusions}

It is shown that the NDP value is constant for a particular substance. Thus, for polystyrene latex, regardless of the particle size $(60 \mathrm{~nm}, 200 \mathrm{~nm})$, this value is $5.0 \pm 0.2$. Within the limits of these values, it is obtained for a mixture of latexes with particle sizes of $60 \mathrm{~nm}$ and $200 \mathrm{~nm}$, i.e. this value does not depend on the standard deviation, intensity and average diameter and depends only on the type of a particular substance. This is also evidenced by the NDP values of sucrose, for which this value is $6.0 \pm 0.1$. For Latex with sizes from $60 \mathrm{~nm}$ to $1000 \mathrm{~nm}, 1.6 \pm 0.2$ is obtained. This means that the NDP value would be a characteristic of a specific individual dispersed material.

\section{Acknowledgments}

This article and the research underlying it would not have been possible without the exceptional support of our families, who always understand our enthusiasm, knowledge and time that we have devoted to every detail of this article.

\section{Conflicts of interest}

The authors declare no relevant financial or other conflict of interest or disclosures in relation to this paper. 


\section{References}

[1] Minakov A.V., Mikhienkova E.I., Zhigarev V.A., Neverov A.L., Rudyak V.Y. A study of the influence of nanoparticles on the properties of drilling fluids Colloid Journal. 2018; 80(4): 418-426.

[2] Kirkland A.I., Hutchison J.L. Nanocharacterisation, Cambridge, RSC Publishing, 2007; 304 p.

[3] Kralchevsky P., Miller R., Ravera F. (Eds.) Colloid and Interface Chemistry for Nanotechnology Taylor \& Francis Group, LLC, Boca Raton, FL, USA, 2013, 554p.

[4] Coluzza I. (Ed.) Design of Self-Assembling Materials Springer International Publishing AG, 2017, 139 p. 